\title{
Identification of Austwickia chelonae as cause of cutaneous granuloma in endangered crocodile lizards using metataxonomics
}

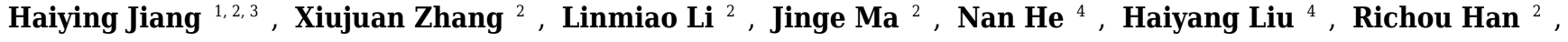 \\ Huiming Li ${ }^{2}$, Zhengjun Wu ${ }^{5}$, Jinping Chen ${ }^{\text {Corresp. } 2}$ \\ ${ }^{1}$ South China Botanical Garden, Chinese Academy of Sciences, Guangzhou, Guangdong, China \\ 2 Guangdong Key Laboratory of Animal Conservation and Resource Utilization, Guangdong Public Laboratory of Wild Animal Conservation and Utilization, \\ Guangdong Institute of Applied Biological Resources, Guangzhou, Guangdong, China \\ 3 University of Chinese Academy of Sciences, Beijing, China \\ 4 Guangdong Luokeng Shinisaurus crocodilurus National Nature Reserve, Shaoguan, Guangdong, China \\ 5 Guangxi Key Laboratory of Rare and Endangered Animal Ecology, Guangxi Normal University, Guilin, Guangxi, China \\ Corresponding Author: Jinping Chen \\ Email address: chenjp@giabr.gd.cn
}

In recent years, crocodile lizards ( Shinisaurus crocodilurus Ahl, 1930), an endangered reptile species, died in diseases each year, especially the rescued and the breeding individuals. However, pathogens underlying these diseases are unclear. In this study, we report our effort in rapidly identifying and isolating the pathogen that causes high mortality in crocodile lizards from Guangdong Luokeng Shinisaurus crocodilurus National Nature Reserve. The typical symptom is cutaneous granuloma in the infected crocodile lizards. Metagenomic next-generation sequencing (mNGS) is a comprehensive approach for sequence-based identification of pathogenic microbes. In this study, 16S rDNA based mNGS was used for rapid identification of pathogens and microscopy and microbe isolation were used to confirm the results. Austwickia chelonae was identified to be the dominant pathogen in the granuloma using 16S rDNA based mNGS. Chinese skinks were used as an animal model to verify the pathogenicity of $A$. chelonae to fulfill Koch's postulates. As expected, subcutaneous inoculation of $A$. chelonae induced granulomas in the healthy Chinese skinks and the $A$. chelonae was re-isolated from the induced granulomas. Therefore, $A$. chelonae was the primary pathogen that caused this high mortality disease, cutaneous granuloma, in crocodile lizards from Guangdong Luokeng Shinisaurus crocodilurus National Nature Reserve. Antibiotics analysis demonstrated that $A$. chelonae was sensitive to cephalothin, minocycline and ampicillin, but not to kanamycin, gentamicin, streptomycin and clarithromycin, suggesting a possible treatment for the infected crocodile lizards. However, surgical resection of the nodules as early as possible was recommended. This study is the first report of pathogenic analysis in crocodile lizards and provides a reference for disease control and conservations of the endangered 
crocodile lizards and other reptiles. In addition, this study indicated that mNGS of lesions could be used to detect the pathogens in animals with benefits in speed and convenient. 
1 Identification of Austwickia chelonae as cause of

2 cutaneous granuloma in endangered crocodile lizards

3 using metataxonomics

4

5

6

7

8

\author{
Haiying Jiang ${ }^{1,2,3}$, Xiujuan $\mathrm{Zhang}^{2}$, Linmiao $\mathrm{Li}^{2}$, Jinge $\mathrm{Ma}^{2}$, Nan $\mathrm{He}^{4}$, Haiyang Liu ${ }^{4}$, Richou \\ $\mathrm{Han}^{2}$, Huiming $\mathrm{Li}^{2}$, Zhengjun $\mathrm{Wu}^{5}$ and Jinping Chen ${ }^{2 *}$ \\ ${ }^{1}$ South China Botanical Garden, Chinese Academy of Sciences, Guangzhou, Guangdong, China \\ ${ }^{2}$ Guangdong Key Laboratory of Animal Conservation and Resource Utilization, Guangdong \\ Public Laboratory of Wild Animal Conservation and Utilization, Guangdong Institute of Applied \\ Biological Resources, Guangzhou, Guangdong, China \\ ${ }^{3}$ University of Chinese Academy of Sciences, Beijing, China \\ ${ }^{4}$ Guangdong Luokeng Shinisaurus crocodilurus National Nature Reserve, Shaoguan, \\ Guangdong, China \\ ${ }^{5}$ Guangxi Key Laboratory of Rare and Endangered Animal Ecology, Guangxi Normal \\ University, Guilin, Guangxi, China \\ Corresponding author:Jinping Chen \\ chenjp@giabr.gd.cn
}

\begin{abstract}
In recent years, crocodile lizards (Shinisaurus crocodilurus Ahl, 1930), an endangered reptile species, died in diseases each year, especially the rescued and the breeding individuals. However, pathogens underlying these diseases are unclear. In this study, we report our effort in rapidly identifying and isolating the pathogen that causes high mortality in crocodile lizards from Guangdong Luokeng Shinisaurus crocodilurus National Nature Reserve. The typical symptom is cutaneous granuloma in the infected crocodile lizards. Metagenomic next-generation sequencing (mNGS) is a comprehensive approach for sequence-based identification of pathogenic microbes. In this study, $16 \mathrm{~S}$ rDNA based mNGS was used for rapid identification of pathogens and microscopy and microbe isolation were used to confirm the results. Austwickia chelonae was identified to be the dominant pathogen in the granuloma using 16S rDNA based mNGS. Chinese skinks were used as an animal model to verify the pathogenicity of $A$. chelonae to fulfill Koch's postulates. As expected, subcutaneous inoculation of $A$. chelonae induced granulomas in the healthy Chinese skinks and the $A$. chelonae was re-isolated from the induced granulomas. Therefore, A. chelonae was the primary pathogen that caused this high mortality disease, cutaneous granuloma, in crocodile lizards from Guangdong Luokeng Shinisaurus crocodilurus National Nature Reserve. Antibiotics analysis demonstrated that A. chelonae was sensitive to
\end{abstract}


cephalothin, minocycline and ampicillin, but not to kanamycin, gentamicin, streptomycin and clarithromycin, suggesting a possible treatment for the infected crocodile lizards. However, surgical resection of the nodules as early as possible was recommended. This study is the first report of pathogenic analysis in crocodile lizards and provides a reference for disease control and conservations of the endangered crocodile lizards and other reptiles. In addition, this study indicated that mNGS of lesions could be used to detect the pathogens in animals with benefits in speed and convenient.

\section{INTRODUCTION}

The crocodile lizard (Shinisaurus crocodilurus Ahl, 1930) is a relict reptile and the only species of the family Shinisauridae. It is a Class I protected species in China, an endangered species on the International Union for Conservation of Nature (IUCN) Red List of Threatened Species (Nguyen et al. 2014), and an appendix I species by the Convention on International Trade in Endangered Species of Wild Fauna and Flora (CITES I). This species is distributed in a few isolated sites in southern China (Guangdong and Guangxi provinces) and northern Vietnam (Quảng Ninh and Bac Giang provinces) (van Schingen et al. 2014; van Schingen et al. 2016). However, anthropogenic disturbances via resource acquisition, habitat destruction and environmental changes, among other factors, have dramatically decreased the population of crocodile lizards in the wild (Huang et al. 2008; Nguyen \& Ziegler 2015). The total number of wild crocodile lizards in China has decreased from 6000 in 1978 to approximately 1200 (Jiang et al. 2017). Recent field surveys in Vietnam also showed that the wild population of crocodile lizards in Vietnam has decreased to fewer than 150 individuals (van Schingen et al. 2016). In addition, the lizard's population continues to show a sharp decline.

However, during the work of rescue and breeding, the crocodile lizards are prone to serious diseases that cause many deaths each year (Jiang et al. 2017). The most frequently disease is skin diseases. For example, in 2014, sixty-nine out of about 200 crocodile lizards died mainly due to a skin disease with a typical symptom of cutaneous granuloma in Guangdong Luokeng $S$. crocodilurus National Nature Reserve. Similar situation was also found in Guangxi Daguishan Crocodile Lizard National Nature Reserve, another skin disease with a typical symptom of limbs ulceration and swelling causes many deaths each year. However, disease diagnosis of wildlife animals can be impeded due to the limited clinic samples and lack of information regarding pathogens that cause these diseases. While thyroid adenocarcinoma, melanomacrophage hyperplasia and suspected seizures have been described, infectious pathogens in crocodile lizards have not been previously reported (Brady et al. 2016). Rapid clinical diagnosis of infectious disease is necessary to facilitate timely therapy.

Microbial culture has been considered as the gold standard of diagnostic methods and the most widely used for bacterial and fungal pathogens, but it is time-consuming and bias for the limitations of the media utilized for growth. Rapid advances in high-throughput sequencing now 
make it possible to comprehensively identify the microbes in a given community, including fastidious and unculturable taxa. Therefore, in recent years, two next-generation sequencing based methods, metagenomics and metataxonomics, have been developed as a fertile area for unbiased microbial pathogenic identification and clinical diagnostics (Fukui et al. 2015; Henan Li 2018; Hilton et al. 2016; Razzauti et al. 2015; Somasekar et al. 2017). Metataxonomics is a gene marker (e.g., 16S or ITS) based high-throughput microbial diversity characterization and metagenomics is the whole genomic shotgun sequencing approach (Marchesi \& Ravel 2015). Metagenomics avoids PCR bias, and it is not restricted to only bacterial or fungal sequences, while metataxonomics can get rid of the signal from host contamination. Therefore, metataxonomics is more suitable for wildlife animals which usually lack genome sequences for mapping references. Besides, to achieve high coverage and depth needed for species identification, metataxonomics is much cheaper than metagenomics. However, reports on the application of metataxonomics in wildlife pathogenic identification remain rare.

This study applied metataxonomics to identify the underlying pathogens of the cutaneous granuloma disease in crocodile lizards. This skin disease caused high mortality of crocodile lizards and occurred every year in the Guangdong Luokeng S. crocodilurus National Nature Reserve. In addition, microscopy and cultivation were used to confirm the results of highthroughput sequencing. Moreover, we tried to fulfill the Koch's postulates, a scientific standard for establishing disease causation (Byrd \& Segre 2016).

\section{MATERIALS \& METHODS}

\section{Ethics statement}

All experimental animal procedures in this study were approved by the Committee on the Ethics of Animal Experiments of the Guangdong Institute of Applied Biological Resources (GIABR180928 and GIABR201027) and followed basic principles.

\section{Animals and sampling}

The sick crocodile lizards were found in the Guangdong Luokeng S. crocodilurus National Nature Reserve $\left(24^{\circ} 31^{\prime} 14^{\prime \prime} \mathrm{N}, 113^{\circ} 20^{\prime} 18^{\prime \prime} \mathrm{E}\right)$. All of the lizards were adults or sub-adults. They were raised in ecological simulation pools. Some of them were rescued from the local wild. The others were born and raised in captivity, and their mother or grandmother was rescued from the local wild. The Nature Reserve raised these lizards to reintroduce them to the wild.

Lesions that formed one or more nodules in the skin of the crocodile lizard were resected, as shown in Fig. 1. The skin nodules were collected and immediately stored in liquid nitrogen. Some nodules were collected from dead animals, and the others were collected by biopsies. 
A total of 16 crocodile lizards were sampled and 33 nodules were collected in this study (Table 1). Five nodules were used for histological examination. Three nodules were used for scanning electronic microscopy (SEM). Four nodules were used for bacteriological cultivation. Eleven nodules were used for high-throughput sequencing to analyze the bacterial and fungal components of the nodules. Six soil samples and two water samples from the crocodile lizard living environment were also collected for sequencing to trace the source of the pathogen. The information of sequenced samples was provided in Table 2.

\section{Histology and SEM}

Five skin nodules were fixed in 4\% paraformaldehyde for structural observation.

For light microscopy, 2-3 $\mu \mathrm{m}$ paraffin sections were prepared and stained with hematoxylineosin (H\&E, Hematoxylin and Eosin Staining Kit C0105, Beyotime Biotechnology; China) and Grocott-Gomori's methenamine silver (GMS, Grocott-Gomori's Methenamine Silver Staining Kit M052, Shanghai Gefan Biotechnology Co., Ltd.; China) stains. Slides for light microscopy were examined using EVOS ${ }^{\circledR}$ FL Auto Cell Imaging System (Thermo Fisher Scientific Inc.; China).

For SEM, samples were dehydrated in a graded ethyl alcohol series from $20 \%$ to $100 \%$. Subsequently, the samples were dried in a $\mathrm{CO}_{2}$ critical point dryer (Leica EM CPD300, Leica Microsystems Inc.; USA), mounted onto aluminum stubs, coated with platinum and examined under a Hitachi S-3400N SEM (Hitachi Ltd.; Japan).

\section{Metataxonomic high-throughput sequencing and analysis}

Total DNA was extracted from the skin nodules, water samples and soil samples using a PowerFecal ${ }^{\circledR}$ DNA Isolation Kit (MOBIO Laboratories, Inc.; USA) with $20 \mathrm{mg} / \mathrm{ml}$ lysozyme. For bacterial community analysis, the V4 hypervariable region of the $16 \mathrm{~S}$ rRNA gene was amplified with the primers 515F (5'-GTGCCAGCMGCCGCGGTAA-3') and 806R (5'GGACTACHVGGGTWTCTAAT-3'). The amplicon library was prepared using TruSeq® DNA PCR-Free Sample Preparation Kit for Illumina (Illumina, Inc.; USA). Sequencing on an Illumina HiSeq platform (250 bp paired-end reads) was performed by the Novogene Corporation (China). In addition, to determine whether the fungal infection was present, the fungal ITS1 gene was amplified. The primers for ITS1 gene amplification were ITS5-1737F (5' GGAAGTAAAAGTCGTAACAAGG-3') and ITS2-2043R (5'GCTGCGTTCTTCATCGATGC-3'), and the expected size of the amplicon was $250-300 \mathrm{bp}$. 2\% agarose gel electrophoresis was used to detect the amplicons.

After sequencing, raw tags were filtered using the QIIME package (Caporaso et al. 2010) to remove low-quality and chimeric sequences. Sequences with $\geq 97 \%$ similarity were assigned to the same operational taxonomic units (OTUs) using Uparse (Edgar 2013). A representative 
142 sequence for each OTU was annotated using Mothur by searching the SILVA database

143 (Threshold = 0.8) (Quast et al. 2013; Schloss et al. 2009). For comparisons between samples, the 144 OTU abundances were normalized by the number of OTUs obtained from the sample with the 145 lowest counts. Multiple sequence alignment and phylogenetic tree were conducted to show the 146 general view of the sequenced bacteria based on top 100 genera using QIIME (Caporaso et al. 147 2010). Flower plots were drawn using R software to compare the similarities and differences in 148 microbes among samples.

\section{Molecular detection of ranavirus}

Co-infection of $A$. chelonae with ranavirus was reported previously (Tamukai et al. 2016). Therefore, the presence of ranavirus in crocodile lizards was examined to confirm the pathogen. Three primer sets were used to detect the ranavirus specific major capsid protein (MCP) gene: RanaM68F (5'-GCACCACCTCTACTCTTATG-3') and BIVMCP154 (5'CCATCGAGCCGTTCATGATG-3'), RanaJP556F (5'-GGTTCTTCCCCTCCCATTCTTCTT3') and RanaJP772R (5'-GGTCATGTAGACGTTGGCCTCGAC-3'), OlT1 (5'GACTTGGCCACTTATGAC-3') and OIT2R (5'-GTCTCTGGAGAAGAAGAAT-3'). The expected sizes of the amplicons were $230 \mathrm{bp}, 217 \mathrm{bp}$ and $500 \mathrm{bp}$, respectively (Stöhr et al. 2013; Une et al. 2014). 2\% agarose gel electrophoresis was used to detect the amplicons. Samples were considered positive if two or three primer sets were positive (Tamukai et al. 2016).

\section{Bacterial isolation and cultivation}

Four granulomas were cut open and spread on Columbia blood agar base plates. The plates were placed at $30^{\circ} \mathrm{C}$ for $24-48 \mathrm{~h}$ to cultivate the bacteria, which were then isolated and purified using repeated plate streaking. The isolated bacteria were incubated in Columbia medium. The DNA of each bacterium was extracted using the TIANamp Bacteria DNA Kit DP302 (Tiangen Biotech (Beijing) Co., Ltd.; China). The 16S rRNA gene was amplified with the universal primers 27Fs (5'-GAAGTCATCATGACCGTTCTGCAAGAGTTTGATCMTGGCTCAG-3') and 1492Rs (5'-AGCAGGGTACGGATGTGCGAGCCTACGGHTACCTTGTTACGACTT-3'), and sequenced with the primers 1S (5'-GAAGTCATCATGACCGTTCTGCA-3') and 2RS (5'AGCAGGGTACGGATGTGCGAGCC-3'). The bacteria were annotated by matching the similarity results in NCBI database using BlastN (https://blast.ncbi.nlm.nih.gov).

\section{Artificial infection}

Because of their endangered status and legality issues, crocodile lizards cannot be experimentally inoculated with bacteria to confirm the pathogen. Instead, another widely distributed lizard species, the Chinese skink (Plestiodon chinensis), was used to verify the pathogenicity of Austwickia chelonae and fulfill the Koch's postulates (Byrd \& Segre 2016). 
All Chinese skinks were adults, captured from wild and temporarily housed in the $57 \mathrm{~cm} * 42$ $\mathrm{cm} * 30 \mathrm{~cm}$ cages in the laboratory for at least one week before inoculation. The bottom of the cages was covered with grass brought back from wild or wood chips. Each cage contained three or four skinks. The cages were kept in secluded rooms to minimize human interference. The skinks were fed with 4-5 cm Zophobas morio larvae and autodrinker.

The candidate pathogen, $A$. chelonae LK16-18, was incubated with Columbia medium for $48 \mathrm{~h}$ at $30^{\circ} \mathrm{C}$ and re-suspended in sterile phosphate buffer saline ( $\left.\mathrm{PBS}, \mathrm{pH}=7.4\right)$ at a concentration of $2.67 * 10^{8} \mathrm{CFU} / \mathrm{ml}$. Ten experimental Chinese skinks were randomly assigned into two groups: the treated group $(\mathrm{N}=5)$ and the negative control group $(\mathrm{N}=5)$. The average weight and snout-vent length of the experimental animals was $26.65 \mathrm{~g}$ and $9.57 \mathrm{~cm}$, respectively. All of the Chinese skinks were clinically healthy, and no nodules or other lesions were found before inoculation. After local disinfection with $75 \%$ ethanol, the treated group were subcutaneously inoculated with $A$. chelonae suspension. The inoculation dose was $20 \mu \mathrm{l} / \mathrm{g}$ (volume of bacterial suspension: weight of animal): $200 \mu \mathrm{l} / 30 \mathrm{~g}$ for the left side of the trunk and tail, $100 \mu \mathrm{l} / 30 \mathrm{~g}$ for the left forelimb and hind limb. The right lateral skin was used to comparative observation. The negative control group were hypodermically inoculated with the same dose of sterile PBS. The disease signs development was observed every day after inoculation for one month or until the experimental Chinese skinks died. When the animals died, the nodules were collected and examined for the presence of $A$. chelonae. The detection methods included 16S rDNA sequencing using the primers 27Fs and 1492Rs, H\&E staining and bacterial isolation as described above.

Moreover, isolated bacteria corresponding to the other three common OTUs in crocodile lizard nodules (Salmonella sp., Acinetobacter sp., Pseudomonas sp.) were also subcutaneously inoculated into Chinese skinks to confirm the pathogeny of $A$. chelonae. Twelve Chinese skinks were randomly assigned into four groups, subcutaneously inoculated with Salmonella enterica LK18-19, Acinetobacter sp. Exi5-53, Pseudomonas protegens Exi5-13, and PBS, respectively, at the same dose and with the same method mentioned above. The average weight and snout-vent length of these skinks was $36.95 \mathrm{~g}$ and $10.78 \mathrm{~cm}$, respectively.

\section{Antibiotic sensitivity test}

Standard disk diffusion test was used to test the antibiotic sensitivity of the candidate pathogen A. chelonae LK16-18. The bacterial suspension was spread onto Columbia blood agar base plates, and disks containing antibiotics (Hangzhou Microbial Reagent Co., Ltd.; China) were sterilely placed on these plates. The plates were incubated at $30^{\circ} \mathrm{C}$ for $48 \mathrm{~h}$, and the disk diffusion zone diameters were recorded. The sensitivity categories were interpreted according to the breakpoints provided in manufactural instruction and the Clinical and Laboratory Standards Institute (CLSI) document M100 (28th Edition) (CLSI 2018). The antibiotic information was listed in Table 3. 


\section{Sequencing data availability}

214 All raw sequences obtained from high-throughput sequencing were deposited into the NCBI 215 Sequence Read Archive (SRA) under the accession number SRP152217. The complete genome 216 sequence of $A$. chelonae LK16-18 has been deposited into NCBI GenBank and published (Jiang 217 et al., 2018). The 16S rRNA gene sequences of $A$. chelonae LK16-18, S. enterica LK18-19, 218 Acinetobacter sp. Exi5-53 and P. protegens Exi5-13 have been deposited into NCBI NR 219 database under the accession numbers MK110377, MK235186, MK235211 and MK235212.

\section{RESULTS}

\section{General description of the disease}

222

This disease was characterized by one or more nodules (Fig. 1). The clinical signs were located on the head, limbs and tail but not on the dorsal or ventral skin (Fig. 1). The most common nodule location was under the tongue (Fig. 1D). Usually, the nodules were located in the skin system. However, there are two exceptions. One lizard was found to have nodules in the stomach and intestinal tract. The other lizard was found to have nodules in the heart (Table 1).

Usually, one nodule was located inside one lesion. Two or more nodules were rarely found, but some crocodile lizards with two or more lesions were observed. The nodules were light yellow or white (Fig. 2). Some advanced nodules were caseous necrotic.

No ectoparasites were found on the surface of lesions.

\section{Results of histology and SEM}

Five nodules used for histological staining showed the same characteristics. Microscopic images at low magnification showed that the nodules were histologically caseous necrotic with a membrane outside the nodule and layer structure inside the nodule (Figs 3A, 3C). A lot of filamentous bacteria were observed inside the nodule (Figs 3B, 3D). The filamentous bacteria occupied the whole nodule. Some mycelia have penetrated into the membrane (Fig. 3D). Scanning electron microscopy also showed a large number of filamentous bacteria across the necrotic tissue in the nodule (Fig. 4).

\section{Detection of bacteria}

16S rDNA based metataxonomic high-throughput sequencing was used to determine the bacterial compositions of 19 samples, including 11 nodules from the skin of crocodile lizards and 8 environmental samples (Table 2). Each sample contained at least 31,635 effective sequences (Fig. S1). The rarefaction curves showed that these sequencing depths were sufficient for 
244

245

246

247

248

249

250

251

252

253

254

255

256

257

258

259

260

261

262

263

264

265

266

267

268

269

270

271

272

273

274

275

276

capturing microbiota in each sample, especially in the nodule samples (Fig. S2). A total of 54 phyla were sequenced in this study. The phylogenetic relationship of top 100 genera was showed in Fig. S3.

The flower plots showed that five OTUs were common to all nodule samples: Austwickia chelonae, Salmonella sp., Acinetobacter sp., Pseudomonas sp. and Halomonas sp. (Fig. 5). Relative abundance analysis showed that these five OTUs were predominant, with relative abundances of $29.0 \%, 8.7 \%, 1.3 \%, 0.82 \%$ and $0.2 \%$, respectively, in the total dataset of nodules. In addition to the five OTUs mentioned above, the dominant bacteria in nodules also included Bacillus, Fusobacterium, Bacteroides, Chryseobacterium and Morganella (Fig. 6). However, these genera were not present in every nodule.

According to Koch's postulates, the pathogen must occur in every case of the disease (Byrd $\&$ Segre 2016). Therefore, the five common bacteria, A. chelonae, Salmonella sp., Acinetobacter sp., Pseudomonas sp. and Halomonas sp., were identified as the candidate pathogens underlying nodules in crocodile lizards. Of these five bacteria, only $A$. chelonae was filamentous, which was consistent with the morphology observed in H\&E staining, GMS staining and SEM (Figs 3-4), while the others were rod-shaped. These results suggest that $A$. chelonae is a candidate pathogen for this crocodile lizard disease.

\section{Detection of fungi}

For fungal infection analysis, only two out of 11 nodule samples showed a clear band, and three samples showed a weak band at the expected size of the ITS1 gene (Fig. 7). In other words, not all of the nodules contained fungi. Moreover, no fungi were observed at GMS staining and SEM micrographs.

\section{Detection of ranavirus}

For primer set RanaM68F/ BIVMCP154, only samples L.LK.17 and L.LK.20 showed a weak band at the expected size of ranavirus MCP gene (Fig. 8A). For primer set RanaJP556F/ RanaJP 772R, no expected sized amplicon was found in all samples (Fig. 8B). For primer set OIT1/ OIT2R, only L.LK.13 showed a band at the expected size of ranavirus MCP gene (Fig. 8C). Therefore, no ranaviruses were considered positively. Besides, no viruses were observed under SEM.

\section{Confirmation of pathogenicity of $A$. chelonae}

To verify the pathogenicity of $A$. chelonae, we isolated and purified the bacteria from nodules resected from crocodile lizard skin using Columbia blood agar base plates, and a pure $A$. chelonae culture (strain LK16-18) was obtained. This bacterium was filamentous under light 
277

278

279

280

281

282

283

284

285

286

287

288

289

290

291

292

293

294

295

296

297

298

299

300

301

302

303

304

305

306

307

308

309

microscopy and SEM. Colonies of $A$. chelonae on Columbia blood agar base plates were beta hemolytic, rough, adherent, and white (Fig. 9).

Half a month after hypodermic inoculation with $A$. chelonae, growing nodules were found on the inoculated sites of the tested Chinese skinks, as expected (Fig. 10). As the nodules growing, the experimental Chinese skinks appeared to eat less or did not eat. In addition, they had difficulty in moving. Moreover, all of the Chinese skinks inoculated with $A$. chelonae died in 21-44 days. The 16S rDNA sequencing results showed that the bacteria in all nodules resected from dead Chinese skinks were $A$. chelonae. Furthermore, $A$. chelonae colonies were re-isolated from the Chinese skink nodules at Columbia blood agar base plates. Filamentous bacteria were observed at H\&E staining micrographs of Chinese skink nodules. Necropsy of the dead Chinese skinks showed that small white pellets were found at the surface of visceral organs. The $16 \mathrm{~S}$ rDNA sequencing results showed that these pellets were bacterial colonies of $A$. chelonae. These results indicated that $A$. chelonae had spread into viscera.

No nodules were found in the skin of experimental Chinese skinks that inoculated with $S$. enterica LK18-19, Acinetobacter sp. Exi5-53, P. protegens Exi5-13, and PBS. Two Chinese skinks died in 4-5 days after inoculated with $P$. protegens Exi5-13. The left limbs were red and swollen, but no nodules were observed at the inoculated sites and internal organs of these two dead animals. The other experimental Chinese skinks were still alive at the end of the experiment.

All the above results led to the conclusion that $A$. chelonae caused the nodules in crocodile lizards reported in this study.

\section{Source of $A$. chelonae}

To trace the source of the pathogen six soil samples and two water samples from the crocodile lizard living environment were sequenced. The results showed that $A$. chelonae was found in some soil and water samples with very low relative abundances (Fig. 6, Table S1).

\section{Sensitivities of $A$. chelonae to antibiotics}

Austwickia chelonae was tested against twelve antibiotics to find effective drugs to control this disease in crocodile lizards (Table 3 ). The most sensitive antibiotic was cephalothin, followed by ampicillin and minocycline. Furthermore, A. chelonae was also sensitive to levofloxacin, rifampicin, erythromycin, ciprofloxacin, and piperacillin. However, this bacterium was not sensitive to kanamycin, gentamicin, streptomycin or clarithromycin.

\section{DISCUSSION}

Declines in crocodile lizard populations continue despite efforts to alleviate the situation. While conservation efforts are currently focused on habitat protection, disease research is an important 
310 issue that needs to be solved for all types of wildlife, especially for endangered animals, such as 311 crocodile lizards, because the disease may significantly increase the risk of extinction for 312 endangered animals (Berger et al. 1998; Daszak et al. 2000; Hellebuyck et al. 2017; Schumacher 313 2006). For example, chytridiomycosis is now recognized as a driver of amphibian population 314 declines (Berger et al. 1998; Fisher et al. 2009). Many nature reserves or zoos treat or breed 315 threatened species with the aim to reintroduce these individuals to their natural habitats. Disease 316 research may improve survival success in these projects, prevent disease vectored into the wild 317 population or other populations following reintroduction, and therefore prevent species 318 extinction.

Both infectious and noninfectious agents can cause dermatosis in lizards. Some primary pathogens that fulfill Koch's postulates have been described; for example, Chrysosporium anamorph of Nannizziopsis vriesii (CANV) is the etiological agent of "yellow fungus disease" in veiled chameleons (Chamaeleo calyptratus) (Paré et al. 2006), and Devrisea agamarum causes dermatitis in agamid lizards and Lesser Antillean iguana (Iguana delicatissima) with skin lesions (Hellebuyck et al. 2009; Hellebuyck et al. 2017). Secondary infections with bacteria or dermatomycosis are common in lizards (Hellebuyck et al. 2012; Mader 2006). Parasites, algae and neoplasms can also affect the skin (Hernandez-Divers \& Garner 2003; Mader 2006; Van As et al. 2016).

In this study, we report the application of metataxonomics in the pathogenic identification of the cutaneous granuloma disease in crocodile lizards, representing the first report of infectious disease in crocodile lizards. For fungal infection analysis, not all nodules contained fungi, which is inconsistent with Koch's postulates. The fungus was not observed in the nodules stained with GMS stains. Therefore, it was concluded that cutaneous granuloma in crocodile lizard was not caused by fungi. For bacterial infection analysis, metataxonomics quickly narrowed the candidate pathogens to just five bacteria (A. chelonae, Salmonella sp., Acinetobacter sp., Pseudomonas sp. and Halomonas sp.) through flower plot and related abundance analysis. Combined with the filamentous feature of microorganisms observed under H\&E staining, GMS staining and SEM, the pathogen (A. chelonae) was identified rapidly and successfully. Pure $A$. chelonae isolated from the nodule was similar to the filamentous bacterium observed by SEM and could induce cutaneous nodules in Chinese skinks (Fig. 10). The other three common bacteria, Salmonella sp., Acinetobacter sp., Pseudomonas sp. did not induce nodule in the experimental Chinese skinks. Taken together, these results well revealed that the skin nodules on the crocodile lizards were caused by $A$. chelonae. As the presence of heart and gastrointestinal nodules in crocodile lizards and the presence of $A$. chelonae in Chinese skink viscera, the authors speculated that the death of crocodile lizards was a result of $A$. chelonae spreading into internal organs. The other bacteria may serve as a secondary infection which also contributes to the death of lizards. For example, the predominant bacteria Salmonella, Fusobacterium, Bacteroides, Chryseobacterium and Morganella are pathogens or conditional pathogens identified in other animals. Secondary infected by these pathogenic or conditional pathogenic bacteria may 
349

350

351

352

353

354

355

356

357

358

359

360

361

362

363

364

365

366

367

368

369

370

371

372

373

374

375

376

377

378

379

380

381

382

383

384

385

386

aggravate the disease situation in crocodile lizards. Although Halomonas sp. was common in the nodules, it had low abundance in nodules and was not isolated in this study. Therefore, Halomonas sp. was not inoculated into Chinese skinks.

Austwickia chelonae is a filamentous, Gram-positive Actinobacterium, which was named Dermatophilus chelonae in the original reference and recently reclassified as a new genus within the Dermatophilaceae family (Hamada et al. 2010). The disease resulting from $A$. chelonae infection is called dermatophilosis. Dermatophilosis has been reported in a number of vertebrates, including a variety of mammals (Aubin et al. 2016; Caron et al. 2017; Gebreyohannes 2013; Lunn et al. 2016; Nemeth et al. 2014), birds (Scaglione et al. 2016; Shearnbochsler et al. 2018), reptiles (Hellebuyck et al. 2012; Tamukai et al. 2016; Wellehan et al. 2004) and humans (Amor et al. 2011; Aubin et al. 2016; Burd et al. 2007). This disease is an important zoonotic skin disease in domestic animals leads to significant economic losses (Ndhlovu \& Masika 2016; Shaibu et al. 2010). Symptoms of dermatophilosis in reptiles include surface crusts, necrotic cellular debris, inflammatory cells, nodular hyperkeratosis, necrosis of the epidermis, and caseous subcutaneous abscessation (Bemis et al. 1999; Mader 2006). The mainly causative agent of dermatophilosis is D. congolensis. Dermatophilosis resulted from $A$. chelonae infection was initially reported in a nose scab on a snapping turtle in Australia (Masters et al. 1995). Austwickia chelonae infection was also detected in king cobra (Ophiophagus hannah) (Wellehan et al. 2004). In lizards, an outbreak of $A$. chelonae co-infected with ranavirus infection was previously reported in inland bearded dragons (Pogona vitticeps) in Japan (Tamukai et al. 2016). In this study, ranavirus was not detected, but every $A$. chelonae infected sample was found to be co-infected with Salmonella sp., Acinetobacter sp., Pseudomonas sp. and Halomonas sp. In addition, the experimental infection also occurred in Chinese skinks (Fig. 10). Besides reptiles, A. chelonae was also detected in free-living hooded crows (Corvus corone cornix), a bird species that had proliferative and crusted foot lesions (Scaglione et al. 2016). Moreover, A. chelonae also produced dermatophilosis lesions onto sheep, rabbits and guinea pigs after inoculation (Masters et al. 1995).

For the treatment modalities of $A$. chelonae infection, surgical resection of the lesions as early as possible and supplementation with antibiotics were recommended. According to the previous study, A. chelonae was susceptible to penicillin, tetracycline, chloramphenicol and sulfafurazol, and resistant to polymyxin, streptomycin and neomycin (Masters et al. 1995). This study revealed that $A$. chelonae was also susceptible to cephalothin, minocycline, levofloxacin, rifampicin, erythromycin, ciprofloxacin and piperacillin while resistant to kanamycin, gentamicin and clarithromycin. Compared with $A$. chelonae and D. congolensis, most information about antibiotics susceptibility are same. However, D. congolensis was resistant to levofloxacin and susceptible to gentamicin (Amor et al. 2011).

For the pathogenic source, A. chelonae was found in some water and soil samples collected on site at the same time, but not detected in gut microbiomes of crocodile lizards (Jiang et al. 
387

388

389

390

391

392

393

394

2017). Therefore, A. chelonae may come from soil or water in the living environment. In that case, environmental disinfection would be an effective preventive method for this disease. This disease has seldom happened nowadays after regularly disinfected the ecological simulation pools using $\mathrm{KMnO}_{4}$. However, further investigation of the exact source of $A$. chelonae is needed, such as the bacteria from food, normal skin microbiota and bacterial flora of the local soil and water. For the mode of $A$. chelonae transmission to crocodile lizards, it is hypothesized that this infection might be caused initially by local trauma, followed by the invasion of $A$. chelonae and other secondary infections. Because crocodile lizards bite each other when they are competing for foods, territory and mates, they are prone to suffering trauma. The most common factors contributing to the pathogenesis of dermatophilosis are skin trauma, prolonged wetting, high humidity, high temperature and concurrent diseases (Gebreyohannes 2013). In addition, pathogen transmission is also affected by environmental stress (e.g., relative overcrowding, habitat migration), climatic conditions, seasonal changes and diets (e.g., food availability and diversity) (Ryser-Degiorgis 2013).

\section{CONCLUSION}

This study is the first to describe, identify and isolate Austwickia chelonae as the primary pathogen underlying cutaneous granulomas in crocodile lizards and the Koch's postulates were fulfilled using Chinese skinks. Secondly, our study highlights the role of potential co-infections of A. chelonae with other bacteria, such as Salmonella, Fusobacterium, Bacteroides, Chryseobacterium and Morganella, in crocodile lizard dermatophilosis. Thirdly, A. chelonae was proved to be sensitive to cephalothin, minocycline, ampicillin, levofloxacin, rifampicin, erythromycin, ciprofloxacin and piperacillin but resistant to kanamycin, gentamicin, streptomycin, and clarithromycin. It is noteworthy that our research indicated that the application of metataxonomics was effective in the identification and diagnosis of pathogens in wildlife animals. Metataxonomics can reduce the turn-around time and provide accurate identification than the conventional culture method. This is a boon for wildlife, whose diseases and pathogens are poorly understood compared to domestic animals.

\section{ACKNOWLEDGMENTS}

The authors thank Prof. Xudong Cao and Dr. Hafiz Ishfaq Ahmad for their critical reading, advices and language modification. Our thanks also go to Dr. Lv-Ping Zhang for his help for SEM microscopy.

\section{REFERENCES}

Amor A, Enríquez A, Corcuera MT, Toro C, Herrero D, and Baquero M. 2011. Is infection by Dermatophilus congolensis underdiagnosed? Journal of Clinical Microbiology 49:449-451. DOI: $10.1128 / \mathrm{jcm} .01117-10$ Aubin GG, Guillouzouic A, Chamoux C, Lepelletier D, Barbarot S, and Corvec S. 2016. Two 
family members with skin infection due to Dermatophilus congolensis : a case report and literature review. European Journal of Dermatology 26:621-622. DOI: 10.1684/ejd.2016.2850

Bemis DA, Patton CS, and Ramsay EC. 1999. Dermatophilosis in captive tortoises. Journal of Veterinary Diagnostic Investigation 11:553-557. DOI: 10.1177/104063879901100616 Berger L, Speare R, Daszak P, Green DE, Cunningham AA, Goggin CL, Slocombe R, Ragan MA, Hyatt AD, and Mcdonald KR. 1998. Chytridiomycosis causes amphibian mortality associated with population declines in the rain forests of Australia and Central America. Proceedings of the National Academy of Sciences of the United States of America 95:90319036.

Brady S, Harrison T, Williams C, Evola M, and Wack RF. 2016. Diagnostic evaluation and treatment of a Chinese crocodile lizard (Shinisaurus crocodilurus) with seizures. Veterinary Record Case Reports 4:e000368. DOI: 10.1136/vetreccr-2016-000368

Burd EM, Juzych LA, Rudrik JT, and Habib F. 2007. Pustular dermatitis caused by Dermatophilus congolensis. Journal of Clinical Microbiology 45:1655-1658. DOI: 10.1128/JCM.00327-07

Byrd AL, and Segre JA. 2016. Adapting Koch's postulates. Science 351:224-226. DOI: 10.1126/science.aad6753

Caporaso JG, Kuczynski J, Stombaugh J, Bittinger K, Bushman FD, Costello EK, Fierer N, Pena AG, Goodrich JK, Gordon JI, Huttley GA, Kelley ST, Knights D, Koenig JE, Ley RE, Lozupone CA, McDonald D, Muegge BD, Pirrung M, Reeder J, Sevinsky JR, Turnbaugh PJ, Walters WA, Widmann J, Yatsunenko T, Zaneveld J, and Knight R. 2010. QIIME allows analysis of high-throughput community sequencing data. Nat Methods 7:335-336. DOI: 10.1038/nmeth.f.303

Caron TJ, Artim SC, Israelsen WJ, Holcombe HR, Fox JG, and Bakthavatchalu V. 2018. Cutaneous dermatophilosis in a meadow jumping mouse (Zapus hudsonius). Comparative Medicine 68:25-30.

CLSI. 2018. Performance standards for antimicrobial susceptibility testing. 28th ed. CLSI supplement M100. Pennsylvania: Clinical and Laboratory Standards Institute.

Daszak P, ., Cunningham AA, and Hyatt AD. 2000. Emerging infectious diseases of wildlife-threats to biodiversity and human health. Science 287:443-449. DOI: 10.1126/science.287.5452.443

Edgar RC. 2013. UPARSE: highly accurate OTU sequences from microbial amplicon reads. Nat Methods 10:996-998. DOI: 10.1038/nmeth.2604

Fisher MC, Garner TW, and Walker SF. 2009. Global emergence of Batrachochytrium dendrobatidis and amphibian chytridiomycosis in space, time, and host. Annual Review of Microbiology 63:291-310. DOI: 10.1146/annurev.micro.091208.073435

Fukui Y, Aoki K, Okuma S, Sato T, Ishii Y, and Tateda K. 2015. Metagenomic analysis for detecting pathogens in culture-negative infective endocarditis. Journal of Infection \& Chemotherapy Official Journal of the Japan Society of Chemotherapy 21:882-884. DOI: 10.1016/j.jiac.2015.08.007 
464

465

466

467

468

469

470

471

472

473

474

475

476

477

478

479

480

481

482

483

484

485

486

487

488

489

490

491

492

493

494

495

496

497

498

499

500

501

502

503

504

Gebreyohannes M. 2013. An overview on dermatophilosis of animals. Journal of Animal Science Advances 3:337-344.

Hamada M, Iino T, Iwami T, Harayama S, Tamura T, and Suzuki K. 2010. Mobilicoccus pelagius gen. nov., sp. nov. and Piscicoccus intestinalis gen. nov., sp. nov., two new members of the family Dermatophilaceae, and reclassification of Dermatophilus chelonae (Masters et al. 1995) as Austwickia chelonae gen. nov., comb. nov. Journal of General \& Applied Microbiology 56:427-436. DOI: 10.1159/000130260

Hellebuyck T, Martel A, and Chiers K. 2009. Devriesea agamarum causes dermatitis in bearded dragons (Pogona vitticeps). Veterinary Microbiology 134:267-271. DOI:

10.1016/j.vetmic.2008.08.021

Hellebuyck T, Pasmans F, Haesebrouck F, and Martel A. 2012. Dermatological diseases in lizards. The Veterinary Journal 193:38-45. DOI: 10.1016/j.tvj1.2012.02.001

Hellebuyck T, Questel K, Pasmans F, Brantegem LV, Philip P, and Martel A. 2017. A virulent clone of Devriesea agamarum affects endangered Lesser Antillean iguanas (Iguana delicatissima). Scientific Report 7:12491. DOI: 10.1038/s41598-017-11874-x

Henan Li HG, Han Meng, Qi Wang, Shuguang Li, Hongbin Chen, Yongjun Li, Hui Wang. 2018. Detection of pulmonary infectious pathogens from lung biopsy tissues by metagenomic nextgeneration sequencing. Frontiers in Cellular \& Infection Microbiology 8:205. DOI: 10.3389/fcimb.2018.00205

Hernandez-Divers SM, and Garner MM. 2003. Neoplasia of reptiles with an emphasis on lizards. Veterinary Clinics of North America: Exotic Animal Practice 6:251-273. DOI:

10.1016/S1094-9194(02)00028-2

Hilton SK, Castronallar E, Pérezlosada M, Toma I, Mccaffrey TA, Hoffman EP, Siegel MO, Simon GL, Johnson WE, and Crandall KA. 2016. Metataxonomic and metagenomic approaches vs. culture-based techniques for clinical pathology. Frontiers in Microbiology 7:484. DOI: $10.3389 /$ fmicb.2016.00484

Huang C, Yu H, Wu Z, Li Y, Wei F, and Gong M. 2008. Population and conservation strategies for the Chinese crocodile lizard (Shinisaurus crocodilurus) in China. Animal Biodiversity and Conservation 31:63-70.

Jiang HY, Huang MW, Lin LB, He N, and Chen JP. 2018. Complete genome sequence of Austwickia chelonae LK16-18, isolated from crocodile lizards. Microbiology Resource Announcements 7: e01140-18. DOI: 10.1128/MRA.01140-18

Jiang HY, Ma JE, Li J, Zhang XJ, Li LM, He N, Liu HY, Luo SY, Wu ZJ, Han RC, and Chen JP. 2017. Diets alter the gut microbiome of crocodile lizards. Frontiers in Microbiology 8:2073. DOI: 10.3389/fmicb.2017.02073

Lunn T, Macgregor J, Munks S, and Carver S. 2016. Dermatophilus congolensis infection in platypus (Ornithorhynchus anatinus), Tasmania, Australia, 2015. Journal of wildlife diseases 52:965-967. DOI: 10.7589/2016-02-030R

Mader DR. 2006. Reptile Medicine and Surgery (Second Edition). Canada: Elsevier.

Marchesi JR, and Ravel J. 2015. The vocabulary of microbiome research: a proposal. Microbiome 3:31. DOI: 10.1186/s40168-015-0094-5 
505

Masters AM, Ellis TM, Carson JM, Sutherland SS, and Gregory AR. 1995. Dermatophilus chelonae sp. nov., isolated from chelonids in Australia. International Journal of Systematic Bacteriology 45:50. DOI: 10.4267/2042/5095

Ndhlovu DN, and Masika PJ. 2016. Bovine dermatophilosis: Awareness, perceptions and attitudes in the small-holder sector of north-west Zimbabwe. Onderstepoort Journal of Veterinary Research 83:1-7. DOI: 10.4102/ojvr.v83i1.1004

Nemeth NM, Ruder MG, Gerhold RW, Brown JD, Munk BA, Oesterle PT, Kubiski SV, and Keel MK. 2014. Demodectic mange, dermatophilosis, and other parasitic and bacterial dermatologic diseases in free-ranging white-tailed deer (Odocoileus virginianus) in the United States from 1975 to 2012. Veterinary Pathology 51:633. DOI: 10.1177/0300985813498783

Nguyen TQ, Hamilton P, and Ziegler T. 2014. Shinisaurus crocodilurus. The IUCN Red List of Threatened Species 2014: e.T57287221A57287235. http://dx.doi.org/10.2305/IUCN.UK.2014-1.RLTS.T57287221A57287235.en. Downloaded on 10 January 2017.

Nguyen TQ, and Ziegler T. 2015. Last chance to See? A review of the threats to and use of the crocodile lizard. TRAFFIC Bulletin 27:19-25.

Paré A, Coyle KA, Sigler L, Rd MA, and Mitchell RL. 2006. Pathogenicity of the Chrysosporium anamorph of Nannizziopsis vriesii for veiled chameleons (Chamaeleo calyptratus). Medical Mycology 44:25-31. DOI: 10.1080/13693780500165461

Quast C, Pruesse E, Yilmaz P, Gerken J, Schweer T, Yarza P, Peplies J, and Glockner FO. 2013. The SILVA ribosomal RNA gene database project: improved data processing and web-based tools. Nucleic Acids Res 41:D590-596. DOI: 10.1093/nar/gks1219

Razzauti M, Galan M, Bernard M, Maman S, Klopp C, Charbonnel N, Vayssiertaussat M, Eloit $\mathrm{M}$, and Cosson JF. 2015. A comparison between transcriptome sequencing and 16S metagenomics for detection of bacterial pathogens in wildlife. PLoS Neglected Tropical Diseases 9:e0003929. DOI: 10.1371/journal.pntd.0003929

Ryser-Degiorgis MP. 2013. Wildlife health investigations: needs, challenges and recommendations. BMC Veterinary Research 9:223. DOI: 10.1186/1746-6148-9-223

Scaglione FE, Cucuzza LS, Pregel P, Chiappino L, Sereno A, Ferroglio E, Pasquetti M, Peano A, and Bollo E. 2016. Dermatophilus spp. and Candida spp. infections in free-living hooded crows (Corvus corone cornix). Journal of Comparative Pathology 154:119-119. DOI: 10.1016/j.jcpa.2015.10.159

Schloss PD, Westcott SL, Ryabin T, Hall JR, Hartmann M, Hollister EB, Lesniewski RA, Oakley BB, Parks DH, Robinson CJ, Sahl JW, Stres B, Thallinger GG, Van Horn DJ, and Weber CF. 2009. Introducing mothur: open-source, platform-independent, communitysupported software for describing and comparing microbial communities. Appl Environ Microbiol 75:7537-7541. DOI: 10.1128/AEM.01541-09

Schumacher J. 2006. Selected infectious diseases of wild reptiles and amphibians. Journal of Exotic Pet Medicine 15:18-24. DOI: 10.1053/j.jepm.2005.11.004

Shaibu SJ, Kazeem HM, Abdullahi US, and Fatihu MY. 2010. The use of polymerase chain reaction in the diagnosis of dermatophilosis from cattle, sheep and goats in Nigeria. Journal of 
Animal \& Veterinary Advances 9:1034-1036. DOI: 10.3923/javaa.2010.1034.1036

Shearnbochsler V, Schulz JL, Dobbs RC, Lorch JM, Waddle JH, and Grear DA. 2018. Novel dermatophilosis and concurrent amyloidosis in sanderlings (Calidris alba) from Louisiana, USA. Journal of Wildlife Diseases 54: 189-192. DOI: 10.7589/2017-04-078

Somasekar S, Lee D, Rule J, Naccache SN, Stone M, Busch MP, Sanders C, Lee WM, and Chiu CY. 2017. Viral surveillance in serum samples from patients with acute liver failure by metagenomic next-generation sequencing. Clinical Infectious Diseases 65:1477-1485. DOI: $10.1093 / \mathrm{cid} / \mathrm{cix} 596$

Stöhr AC, Blahak S, Heckers KO, Wiechert J, Behncke H, Mathes K, Günther P, Zwart P, Ball I, and Rüschoff B. 2013. Ranavirus infections associated with skin lesions in lizards. Veterinary research 44:84. DOI: 10.1186/1297-9716-44-84

Tamukai K, Tokiwa T, Kobayashi H, and Une Y. 2016. Ranavirus in an outbreak of dermatophilosis in captive inland bearded dragons (Pogona vitticeps). Veterinary Dermatology 27:99. DOI: 10.1111/vde.12288

Une Y, Kudo T, Tamukai Ki, and Murakami M. 2014. Epidemic ranaviral disease in imported captive frogs (Dendrobates and Phyllobates spp.), Japan, 2012: a first report. JMM Case Reports 1. DOI: 10.1099/jmmcr.0.001198

Van As J, Cook CA, Netherlands EC, and Smit NJ. 2016. A new lizard malaria parasite Plasmodium intabazwe n. sp.(Apicomplexa: Haemospororida: Plasmodiidae) in the Afromontane Pseudocordylus melanotus (Sauria: Cordylidae) with a review of African saurian malaria parasites. Parasites \& vectors 9:437. DOI: 10.1186/s13071-016-1702-3 van Schingen M, Duc Le M, Thi Ngo H, The Pham C, Quy Ha Q, Quang Nguyen T, and Ziegler T. 2016. Is there more than one crocodile lizard? An integrative taxonomic approach reveals Vietnamese and Chinese Shinisaurus crocodilurus represent separate conservation and taxonomic units. Der Zoologische Garten 85:240-260. DOI: 10.1016/j.zoolgart.2016.06.001 van Schingen M, Ihlow F, Nguyen TQ, Ziegler T, Bonkowski M, Wu Z, and Rödder D. 2014. Potential distribution and effectiveness of the protected area network for the crocodile lizard, Shinisaurus crocodilurus (Reptilia: Squamata: Sauria). Salamandra 50:71-76.

Wellehan JF, Turenne C, Heard DJ, Detrisac CJ, and O'Kelley JJ. 2004. Dermatophilus chelonae in a king cobra (Ophiophagus hannah). Journal of Zoo \& Wildlife Medicine 35:553-556. DOI: 10.1638/03-099 
Table $\mathbf{1}$ (on next page)

Information of sample collection 
1 Table 1 Information of sample collection

\begin{tabular}{|c|c|c|c|c|}
\hline $\begin{array}{l}\text { Animal } \\
\text { Number }\end{array}$ & $\begin{array}{l}\text { Number of } \\
\text { Nodule }\end{array}$ & Location of Nodules & Treatment of Nodule & Sample date \\
\hline LK3 & 1 & Under the tongue & Stored & 20160524 \\
\hline LK4 & 3 & Right hind limb & DNA extraction for one nodule & 20160524 \\
\hline LK5 & 1 & Under the tongue & Paraffin section & 20160524 \\
\hline LK0525 & 5 & Stomach and intestinal tract & Stored & 20160525 \\
\hline LK6 & 1 & Submental triangle & $\begin{array}{l}\text { DNA extraction, bacteriological } \\
\text { cultivation }\end{array}$ & 20160627 \\
\hline LK7 & 3 & Not recorded & DNA extraction for one nodule & 2014 \\
\hline LK8 & 1 & Around cloaca & Paraffin section & 2014 \\
\hline LK9 & 2 & Not recorded & Paraffin section for one nodule & 2014 \\
\hline LK13 & 1 & Head & DNA extraction & 20160628 \\
\hline LK16 & 4 & Head & DNA extraction for one nodule & 20160824 \\
\hline LK17 & 2 & Head, around cloaca & DNA extraction for one nodule & 20160824 \\
\hline LK18 & 3 & Submental triangle & DNA extraction for one nodule & 20160824 \\
\hline LK19 & 1 & Around cloaca & DNA extraction & 20160824 \\
\hline LK20 & 2 & Heart & Stored & 20170505 \\
\hline LK21 & 1 & The right of the lower jaw & $\begin{array}{l}\text { DNA extraction, bacteriological } \\
\text { cultivation, SEM, paraffin section }\end{array}$ & 20170731 \\
\hline LK22 & 2 & Under the tongue, right forelimb & $\begin{array}{l}\text { DNA extraction, bacteriological } \\
\text { cultivation, SEM, paraffin section }\end{array}$ & 20170731 \\
\hline
\end{tabular}

2 
Table 2 (on next page)

Sample information of high-throughput sequencing 
1 Table 2 Sample information of high-throughput sequencing

\begin{tabular}{|c|c|c|c|}
\hline Group & Sample & Location & $\begin{array}{l}\text { Sample } \\
\text { date }\end{array}$ \\
\hline Nodule & L.LK.07 & Not recorded & 2014 \\
\hline Nodule & L.LK.4L & Right hind limb & 20160524 \\
\hline Nodule & L.LK.13 & Head & 20160628 \\
\hline Nodule & L.LK.06 & Submental triangle & 20160627 \\
\hline Nodule & L.LK.16 & Right lower jaw & 20170731 \\
\hline Nodule & L.LK.17 & Under the tongue & 20170731 \\
\hline Nodule & L.LK.18 & Right forelimb & 20170731 \\
\hline Nodule & L.LK.19 & Around cloaca & 20160824 \\
\hline Nodule & L.LK.20 & Submental triangle & 20160824 \\
\hline Nodule & L.LK.21 & Head & 20160824 \\
\hline Nodule & L.LK.22 & Head & 20160824 \\
\hline Water & SW.LK.03 & $\begin{array}{l}\text { Pool where crocodile lizards with nodules were } \\
\text { found }\end{array}$ & 20160715 \\
\hline Water & SW.LK.04 & $\begin{array}{l}\text { Pool where crocodile lizards with nodules were } \\
\text { found }\end{array}$ & 20160715 \\
\hline Soil & SS.LK.03 & $\begin{array}{l}\text { Pool where crocodile lizards with nodules were } \\
\text { found }\end{array}$ & 20160715 \\
\hline Soil & SS.LK.04 & $\begin{array}{l}\text { Pool where crocodile lizards with nodules were } \\
\text { found }\end{array}$ & 20160715 \\
\hline Soil & SS.LK.05 & $\begin{array}{l}\text { Pool where crocodile lizards with nodules were } \\
\text { found }\end{array}$ & 20160824 \\
\hline Soil & SS.LK.06 & $\begin{array}{l}\text { Pool where crocodile lizards with nodules were } \\
\text { found }\end{array}$ & 20160824 \\
\hline Soil & SS.LK.07 & $\begin{array}{l}\text { Pool where crocodile lizards with nodules were } \\
\text { not found }\end{array}$ & 20160824 \\
\hline Soil & SS.LK.08 & $\begin{array}{l}\text { Pool where crocodile lizards with nodules were } \\
\text { not found }\end{array}$ & 20160824 \\
\hline
\end{tabular}




\section{Table 3 (on next page)}

Sensitivities of Austwickia chelonae to antibiotics. 
3 Table 3 Sensitivities of Austwickia chelonae to antibiotics.

Interpretive Categories and

\begin{tabular}{|c|c|c|c|c|c|c|c|}
\hline \multirow[t]{2}{*}{ No. } & \multirow[t]{2}{*}{ Antibiotics } & \multirow[t]{2}{*}{$\begin{array}{l}\text { Disk Content } \\
\qquad(\mu \mathrm{g})\end{array}$} & \multirow[t]{2}{*}{$\begin{array}{l}\text { Zone Diameter } \\
\qquad(\mathrm{mm})\end{array}$} & \multirow[t]{2}{*}{$\begin{array}{l}\text { Interpretive } \\
\text { Categories }\end{array}$} & \multicolumn{3}{|c|}{$\begin{array}{l}\text { Zone Diameter Breakpoints } \\
\qquad(\mathrm{mm})\end{array}$} \\
\hline & & & & & $\mathrm{S}$ & I & $\mathrm{R}$ \\
\hline 1 & Cephalothin & 30 & 68 & S & $\geqslant 18$ & $15-17$ & $\leqslant 14$ \\
\hline 2 & Ampicillin & 10 & 48 & $\mathrm{~S}$ & $\geqslant 17$ & $14-16$ & $\leqslant 13$ \\
\hline 3 & Minocycline & 30 & 42 & $\mathrm{~S}$ & $\geqslant 19$ & $15-18$ & $\leqslant 14$ \\
\hline 4 & Levofloxacin & 5 & 37 & $\mathrm{~S}$ & $\geqslant 17$ & $14-16$ & $\leqslant 13$ \\
\hline 5 & Rifampicin & 5 & 34 & S & $\geqslant 20$ & $17-19$ & $\leqslant 16$ \\
\hline 6 & Erythromycin & 15 & 29 & $\mathrm{~S}$ & $\geqslant 23$ & $14-22$ & $\leqslant 13$ \\
\hline 7 & Ciprofloxacin & 5 & 23 & $\mathrm{~S}$ & $\geqslant 21$ & $16-20$ & $\leqslant 15$ \\
\hline 8 & Piperacillin & 100 & 32 & $\mathrm{~S}$ & $\geqslant 21$ & $18-20$ & $\leqslant 17$ \\
\hline 9 & Kanamycin & 30 & - & $\mathrm{R}$ & $\geqslant 18$ & $14-17$ & $\leqslant 13$ \\
\hline 10 & Gentamicin & 10 & - & $\mathrm{R}$ & $\geqslant 15$ & $13-14$ & $\leqslant 12$ \\
\hline 11 & Streptomycin & 10 & - & $\mathrm{R}$ & $\geqslant 15$ & $12-14$ & $\leqslant 11$ \\
\hline 12 & Clarithromycin & 15 & - & $\mathrm{R}$ & $\geqslant 18$ & $14-17$ & $\leqslant 13$ \\
\hline
\end{tabular}

4 


\section{Figure 1}

Locations of cutaneous granulomas in crocodile lizards.

The arrows indicate the lesions. One or more nodules were found under the lesion. (A) Right forelimb. (B) Right hind limb. (C) Head. (D) Under the tongue. (E) Around cloaca. (F) The right of the lower jaw. (G) Lower jaw. (H) Submental triangle. Photo credit: (A-C, E-F) Jinping Chen. (D,G-H) Nan He.
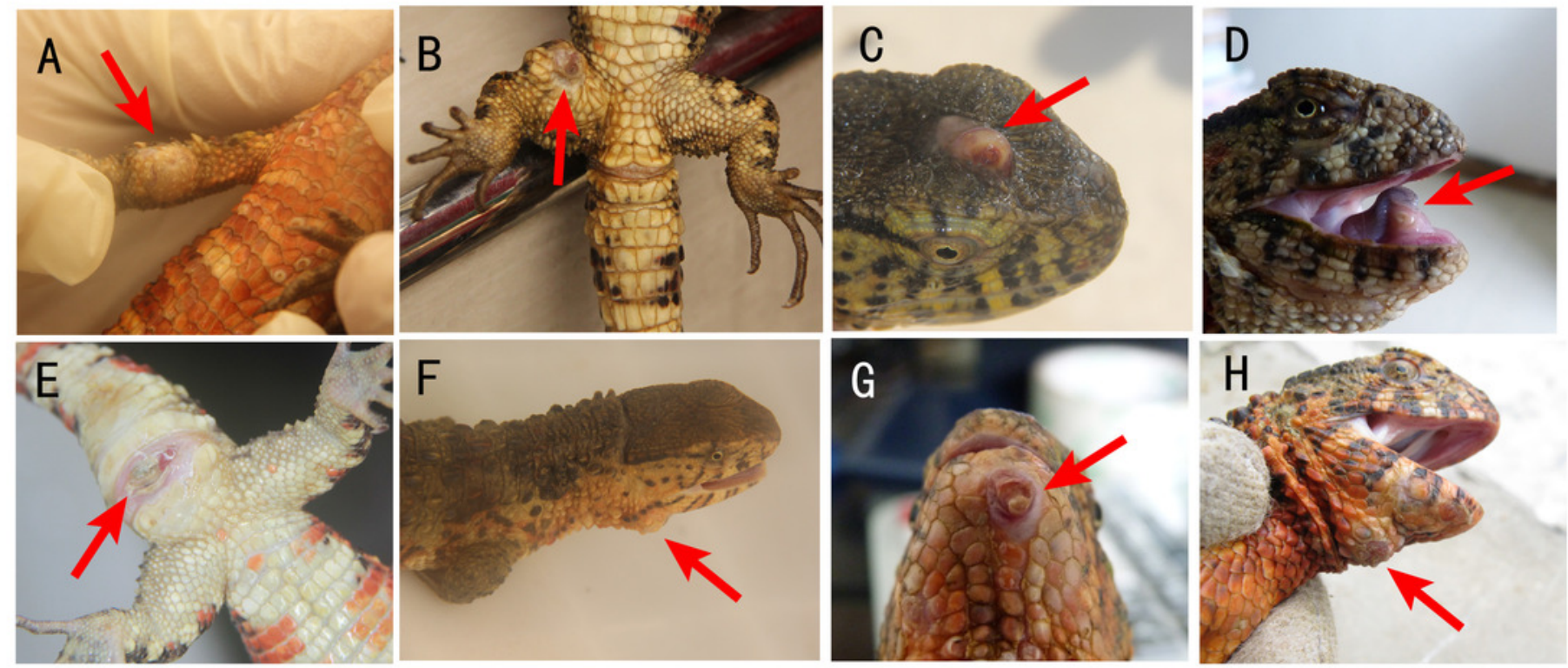
Figure 2

Nodules in the lesions of crocodile lizards.

Photo credit: Jinping Chen.
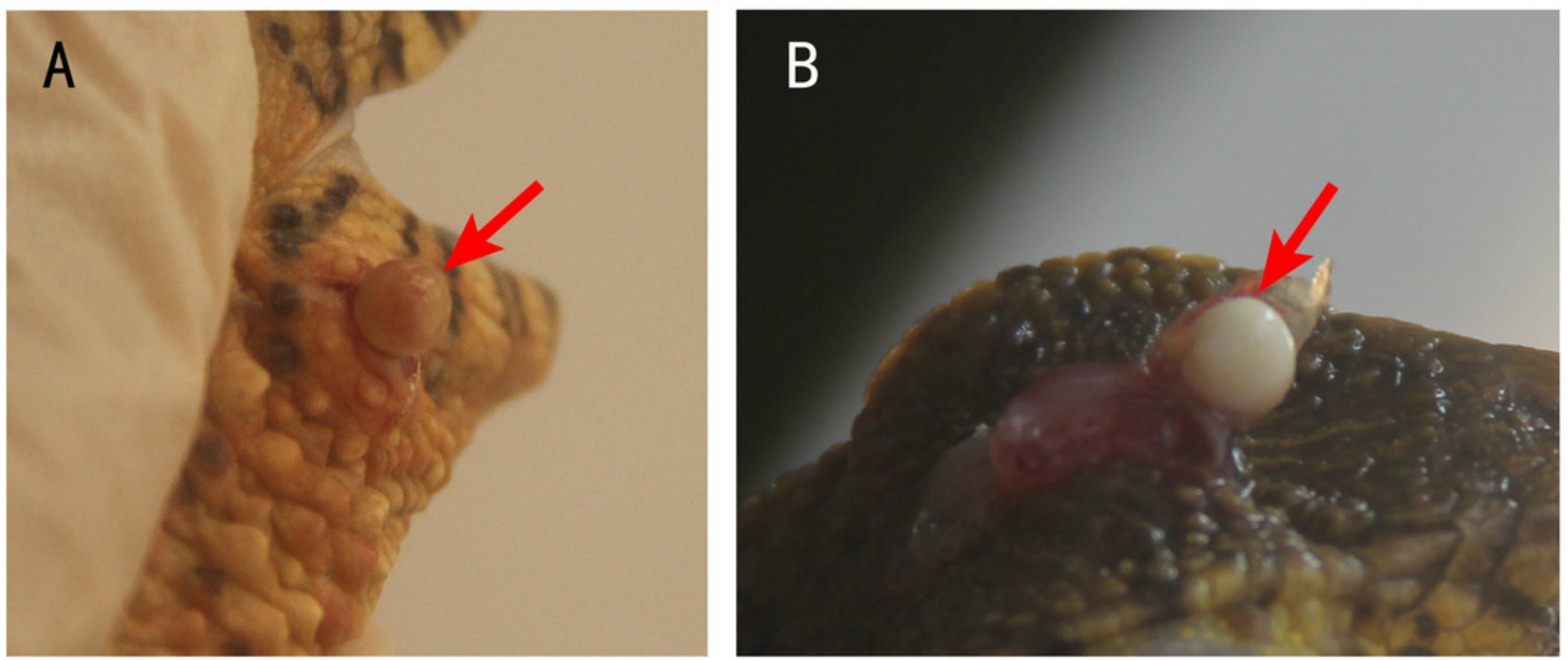


\section{Figure 3}

Histological micrographs of nodules .

(A) The multi-layered structure of the nodule. H\&E staining. Scale bar $=400 \mu \mathrm{m}$. (B) A high number of filamentous bacteria were stained in dark blue inside the nodule. H\&E staining.

Scale bar $=100 \mu \mathrm{m}$. (C) The membrane and multi-layered structure of the nodule. GMS staining. Scale bar $=400 \mu \mathrm{m}$. (D) Filamentous bacteria were stained in black . GMS staining.

Scale bar $=100 \mu \mathrm{m}$.
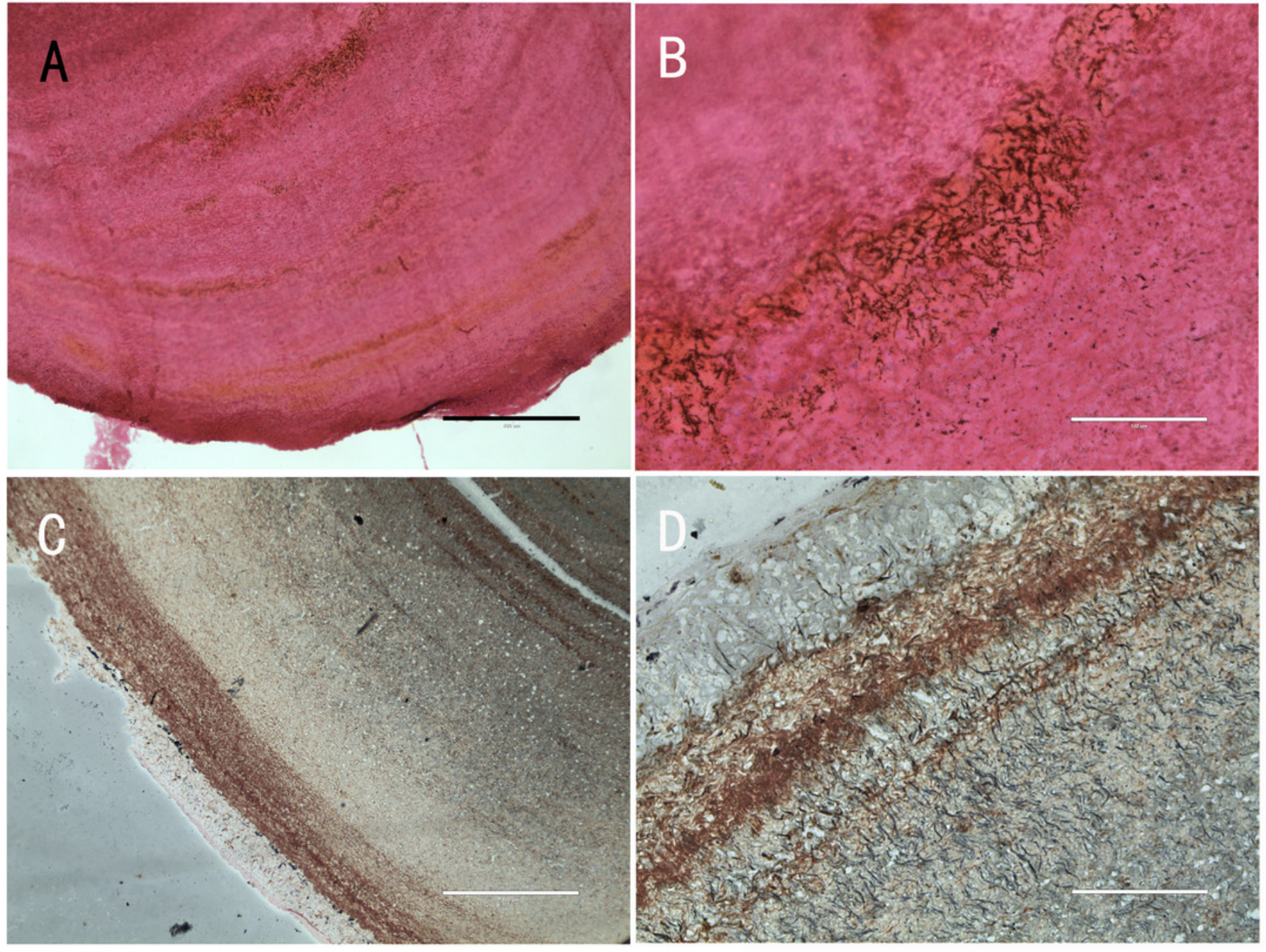


\section{Figure 4}

SEM image of the inside of a nodule.

Scale bar $=15 \mu \mathrm{m}$

*Note: Auto Gamma Correction was used for the image. This only affects the reviewing manuscript. See original source image if needed for review.

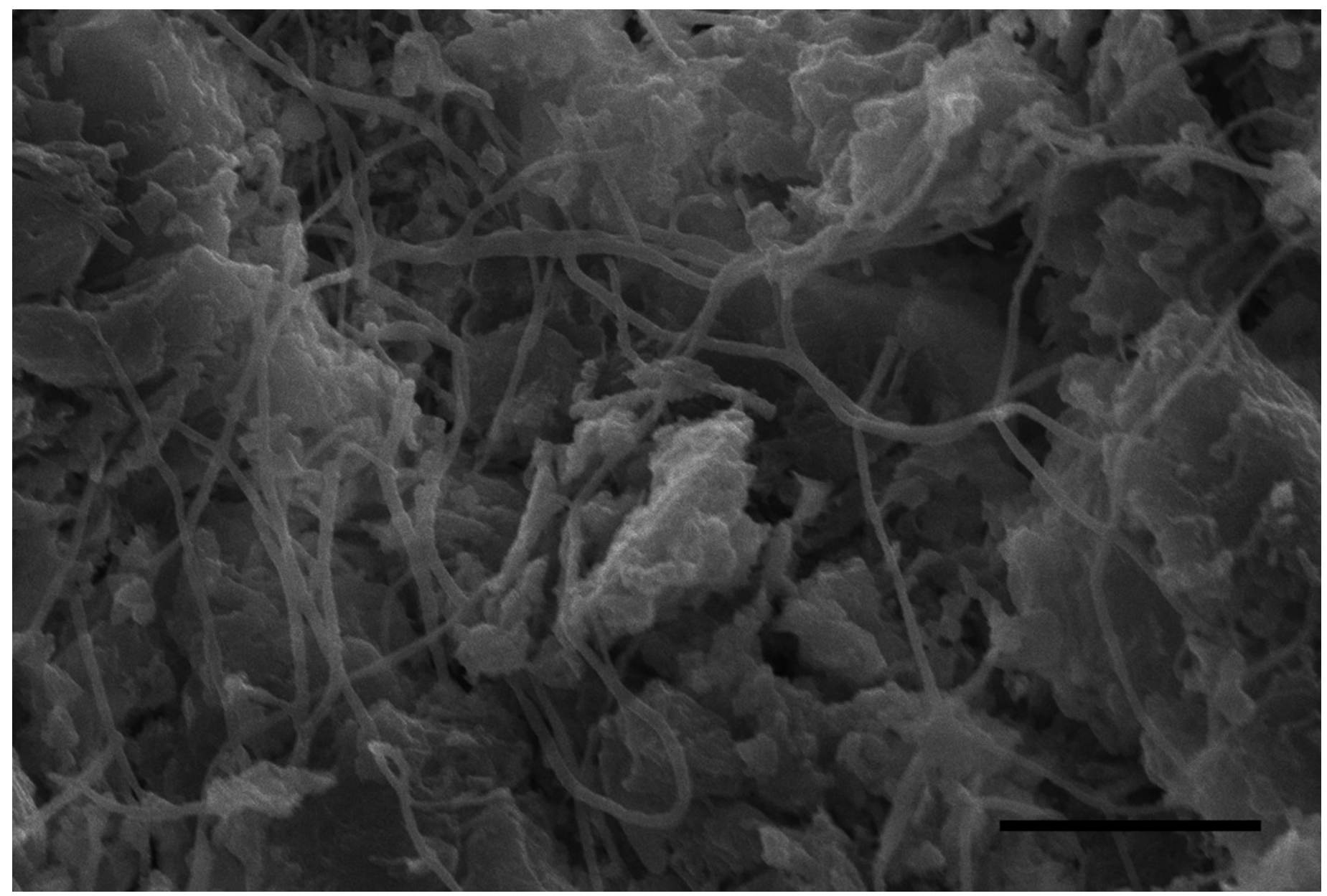




\section{Figure 5}

Flower plot conducted based on OTUs.

The core number in the middle represents the number of OTUs common to all samples. The numbers on the petals represent the number of OTUs unique to the sample.
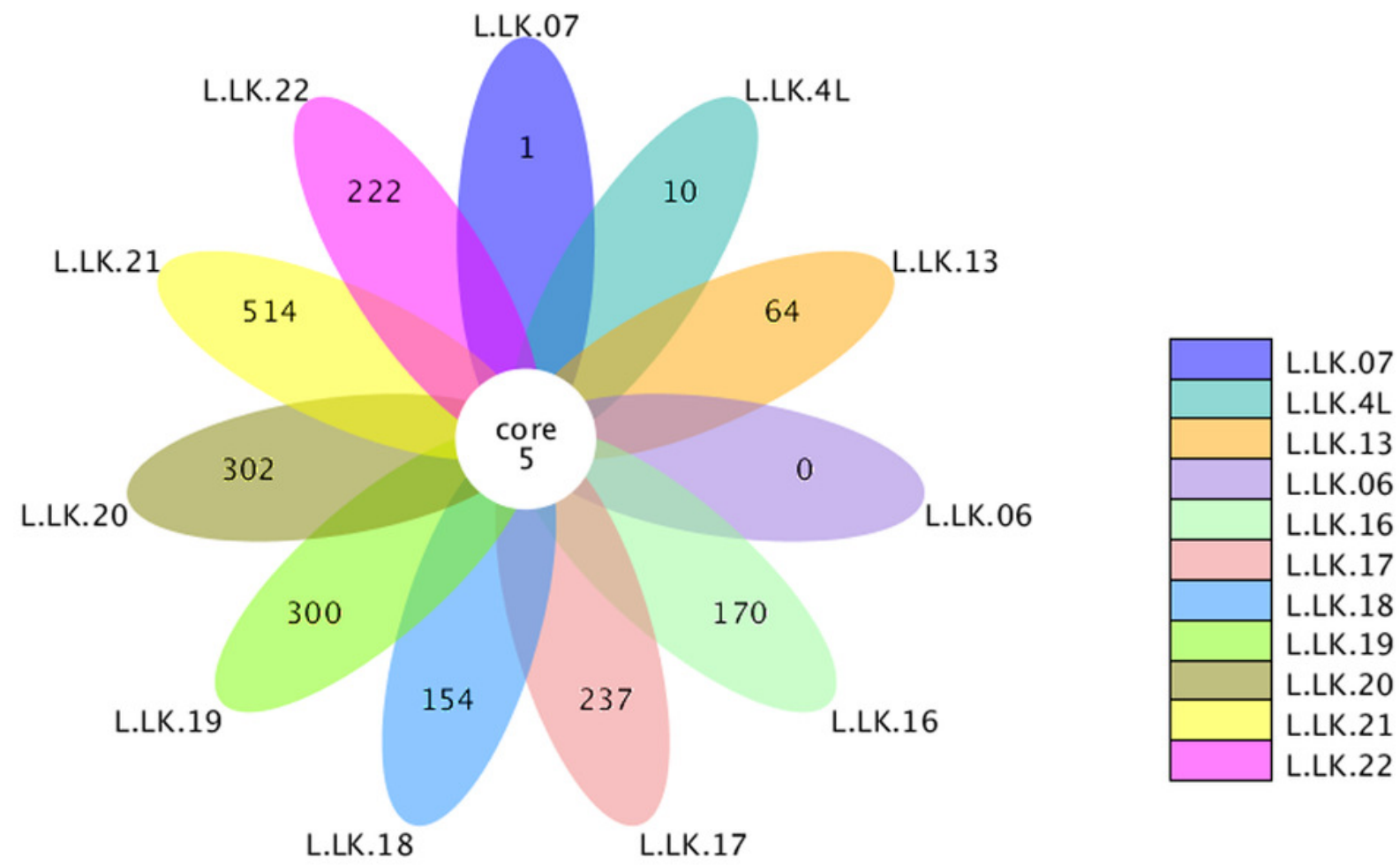


\section{Figure 6}

\section{Relative abundances of nodule and environmental bacteria at the general level.}

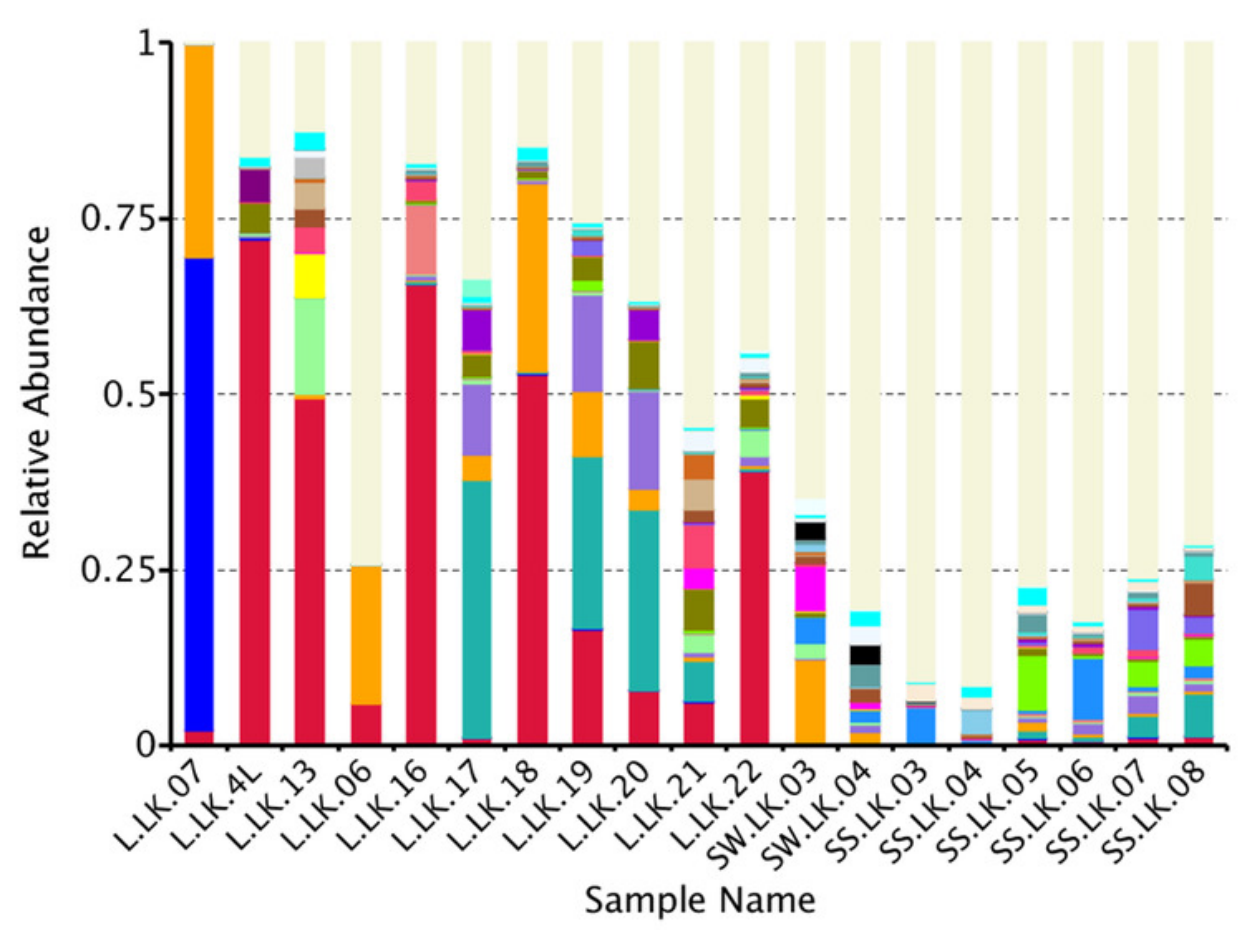

Others

Chromobacterium

Petrimonas

Pseudomonas

H16

Candidatus_Nitrosotalea

- Leptolyngbya

Niabella

unidentified_Xanthomonadaceae

Aeromonas

Neisseria

Flavobacterium

- Stenotrophomonas

Deinococcus

Caenimonas

Vulcaniibacterium

- unidentified_Peptostreptococcaceae

Leptotrichia

Acinetobacter

unidentified_Mitochondria

Elizabethkingia

Morganella

Streptococcus

- unidentified_Chloroplast

- Proteiniclasticum

Chryseobacterium

Bacteroides

- Salmonella

Fusobacterium

Bacillus

Austwickia 


\section{Figure 7}

Agarose gel (2\%) electrophoresis diagram of ITS1 gene amplicons.

M, marker; +, positive control (fungus Ophiocordyceps sinensis); 1, L.LK.4L; 2, L.LK.06; 3, L.LK.07; 4, L.LK.13; 5, L.LK16; 6, L.LK.17; 7, L.LK.18; 8, L.LK.19; 9, L.LK.20; 10, L.LK.21; 11, L.LK.22; -, negative control (water).

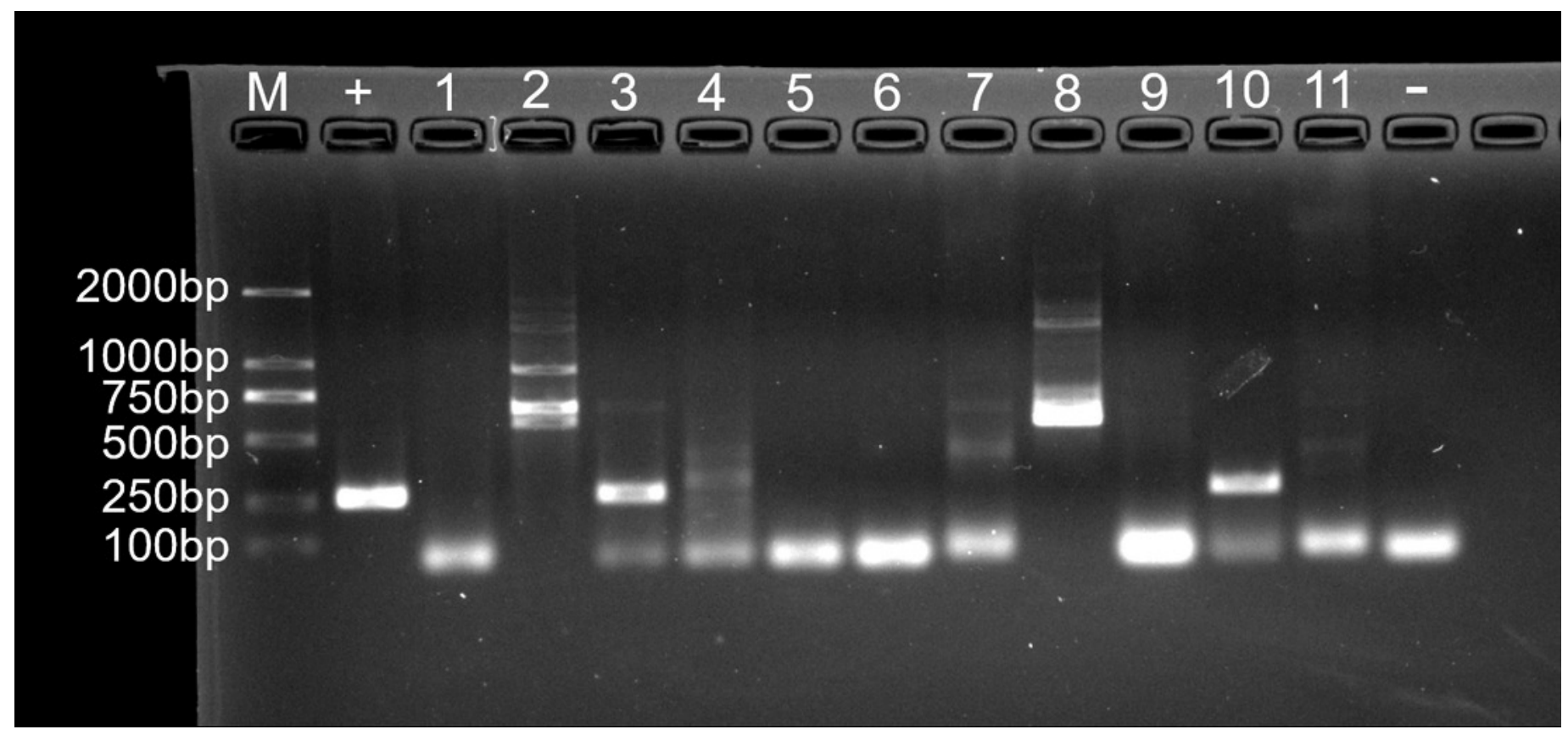




\section{Figure 8}

Agarose gel (2\%) electrophoresis diagram of ranavirus specific MCP gene amplicons.

(A) Amplicons of primer set RanaM68F/ BIVMCP154. The expected size was 230 bp. M, marker; 1, L.LK.16; 2, L.LK.17; 3, L.LK.19; 4, L.LK.20; 5, L.LK21; 6, L.LK.22; 7, L.LK.07; 8, L.LK.13. (B) Amplicons of primer set RanaJP556F/ RanaJP 772R. The expected size was 217 bp. M, marker; 1, L.LK.16; 2, L.LK.17; 3, L.LK.19; 4, L.LK.20; 5, L.LK21; 6, L.LK.22; 7, L.LK.07; 8, L.LK.13; 9, L.LK.18. (C) Amplicons of primer set OIT1/ OIT2R. The expected size was 500 bp. M, marker; 1, L.LK.16; 2, L.LK.17; 3, L.LK.19; 4, L.LK.20; 5, L.LK21; 6, L.LK.22; 7, L.LK.07; 8, L.LK.13.

*Note: Auto Gamma Correction was used for the image. This only affects the reviewing manuscript. See original source image if needed for review.
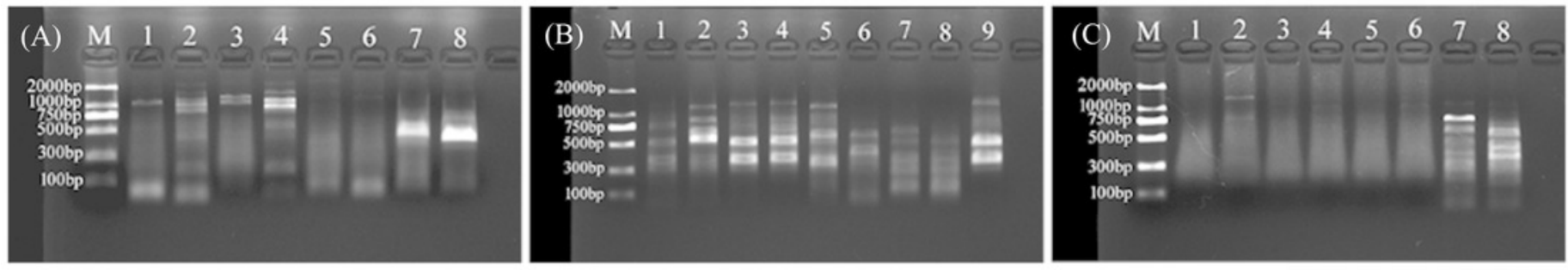
Figure 9

Beta hemolysis of Austwickia chelonae on a Columbia blood agar base plate.

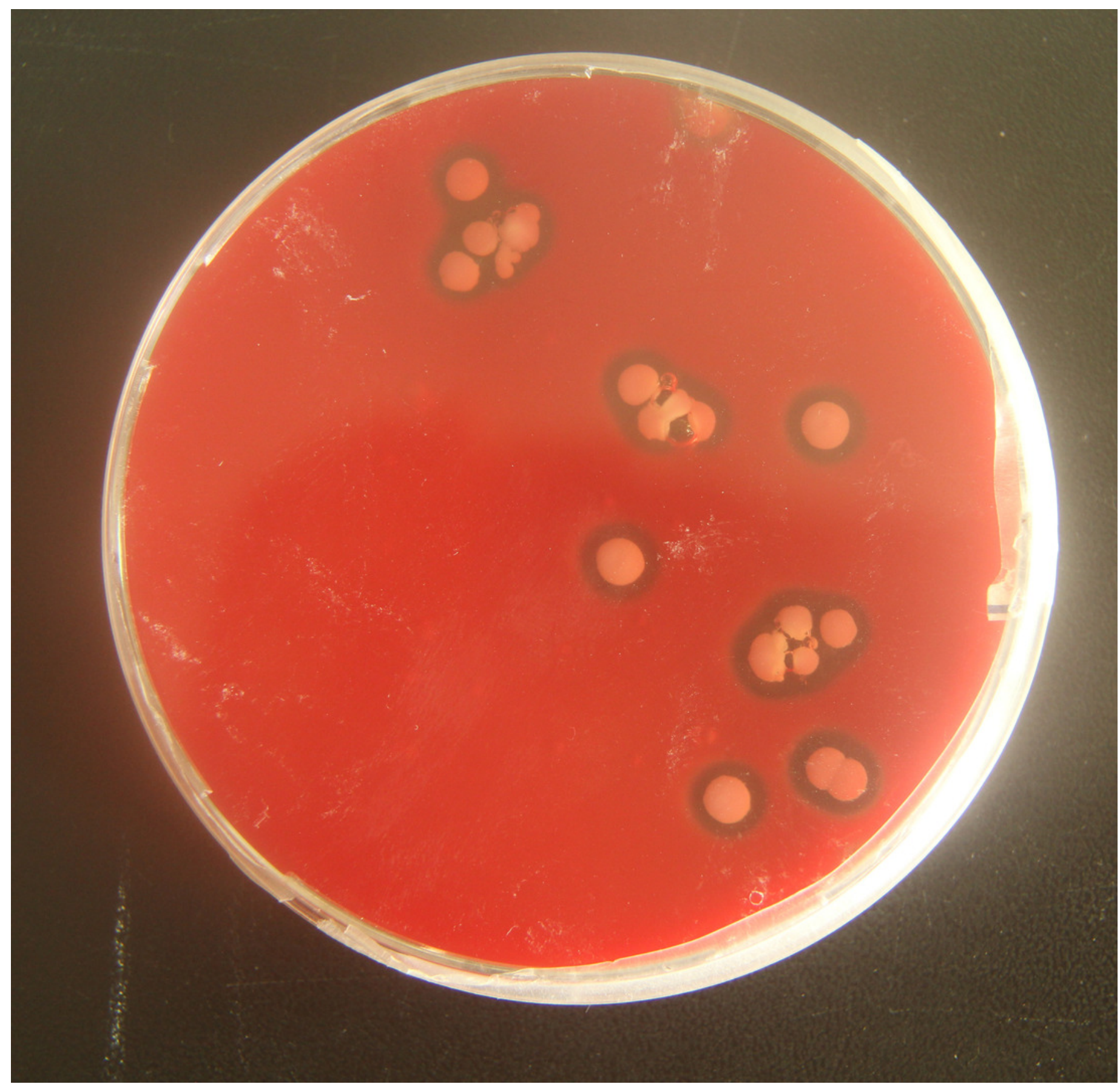




\section{Figure 10}

Chinese skink hypodermically inoculated with Austwickia chelonae (photo time: 44 days after inoculation).

Arrows note the visible nodules on the left side compared with the right side. Photo credit: Haiying Jiang.

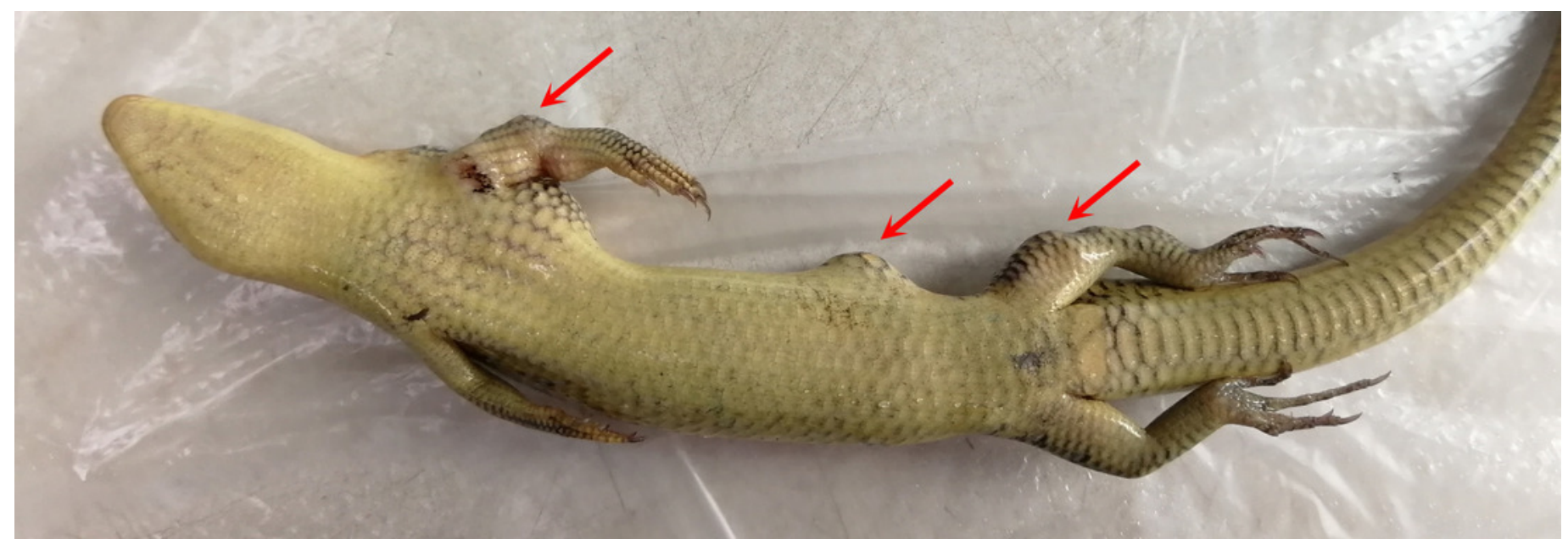

